\title{
Pneumocystis prophylaxis for all, some, or no HIV-infected infants less than one year of age: A decision analysis approach
}

Upton D AlLEN, MBBS, MSC, FRCPC, StANLEY E READ, MD, PHD, FRCPC

\begin{abstract}
UD Allen, SE Read. Pneumocystis prophylaxis for all, some, or no HIV-infected infants less than one year of age: A decision analysis approach. Can $J$ Infect Dis 1993:4(6):333-340. Pneumocystis carinit pneumonia (PCP) is associated with significant mortality and morbidity among infants infected with human immunodeficiency virus (HIV). The preferred prophylaxis strategy for such infants is a subject of debate. Medical decision analysis was used to determine the preferred strategy for primary PCP prophylaxis among asymptomatic HIV-infected infants less than one year of age, and to determine the thresholds at which different variables influence decision making. Utility measures (health state preference values) were used to determine whether prophylaxis should be given to all, some or no infants. In this regard, some infants would receive prophylaxis if baseline CD4 counts are fewer than 1500 cells $/ \mathrm{mm}^{3}$. The results suggest that the preferred option is to give prophylaxis to all asymptomatic HIV-infected infants despite CD4 counts, if the risk of PCP is equal to or greater than 25\%. However, if the risk of PCP is less than $25 \%$, prophylaxis is recommended for those infants with CD4 counts of fewer than 1500 cells $/ \mathrm{mm}^{3}$. The results complement current guidelines regarding PCP prophylaxis for HIV-infected infants.
\end{abstract}

Key Words: Decision analysis, Pneumocystis, Prophylaxis

\section{Prophylaxie de la pneumocystite chez les nourrissons de moins d'un an (chez tous, certains, ou aucun): approche analytique décisionnelle}

RÉSUMÉ: La pneumonie à Pneumocystis carinii (PPC) est associée à des taux de mortalité et de morbidité importants chez les nourrissons infectés au virus de l'immunodéficience humaine (VIH). La stratégie prophylactique préférée chez ces nourrissons est sujette à débat. Une approche analytique décisionnelle médicale a été utilisée pour déterminer la meilleure stratégie à adopter en matière de prophylaxie primaire de la PPC chez les nourrissons asymptomatiques infectés au VIH de moins d'un an et pour déterminer les seuils auxquels différentes variables influent sur la prise de décision. Des mesures d'utilité (valeurs relatives à l'état de santé) ont été utilisées pour déterminer si la prophylaxie devrait être administrée à tous les nourrissons, à certains d'entre eux ou à aucun d'entre eux. À cet égard, certains nourrissons recevraient une prophylaxie si leur numération de CD4 de base était inférieure à 1500 cellules $/ \mathrm{mm}^{3}$. Les résultats suggèrent que la meilleure option est d'administrer une prophylaxie à tous les nourrissons asymptomatiques infectés au VIH en dépit des numérations de CD4 si le risque de PPC est égal ou supérieur à $25 \%$. Cependant, si le risque de PPC est inférieur à $25 \%$, la prophylaxie est recommandée pour les nourrissons dont les numérations de CD4 sont inférieures à 1500 cellules $/ \mathrm{mm}^{3}$. Les résultats complètent les directives actuelles au sujet de la prophylaxie de la PPC chez les nourrissons infectés au VIH.

Division of Infectious Diseases, Department of Pediatrics, The Hospital for Sick Children, Toronto, Ontario

Correspondence and reprints: Dr Upton Allen, Division of Infectious Diseases, The Children's Hospital of Eastern Ontario, 401

Smyth Road, Ottawa, Ontario K1H 8L1. Telephone (613)737-2651, Fax (613)738-4832

Presented in part at the 31st Interscience Conference on Antimicrobial Agents and Chemotherapy, Chicago, 1991

Received for publication October 26, 1992. Accepted February 10, 1993 
$P^{\prime}$ NEUMOCYSTIS CARINII PNEUMONIA (PCP) REPRESENTS A major burden of illness for adults and children infected with the human immunodeficiency virus (HIV). Sixty to eighty per cent of adult patients ultimately develop PCP if they do not receive PCP prophylaxis at the appropriate time (1-2). While the precise disease burden is not as well defined in the pediatric population as it is in the adult population, it has been established that PCP occurs in up to $53 \%$ of children with HIV infection (2), and is a major cause of mortality and morbidity (3-5). Among HIV-infected infants, those presenting with PCP during the first year of life have the worst prognosis (3-4).

Adult patients who are HIV-infected are considered to be at high risk of developing PCP if their CD4 counts are less than 200 cells $/ \mathrm{mm}^{3}$ or if acquired immunodeficiency syndrome (AIDS)-defining syndromes are present (6). However, it has been established that among HIV-infected children under one year of age, the CD4 count based on the criterion used in adults is not a reliable indicator of the risk of developing PCP (7-10). Therefore, besides giving prophylaxis to all HIV-infected children who have had a prior episode of PCP, as well as those with AIDS-defining conditions (other than lymphoid interstitial pneumonitis), it has been suggested that all HIV-infected children under one year of age should receive PCP prophylaxis regardless of CD4 counts $(7-8,11)$. With respect to the role of a specific cut-off level for CD4 counts as a guide for prophylaxis, recent Centers for Disease Control and Prevention (CDC) guidelines recommend prophylaxis for those infants with fewer than $1500 \mathrm{CD} 4$ cells $/ \mathrm{mm}^{3}$ as well as those with a CD4 cell count of less than 20\% (12).

Prophylaxis strategies were examined using medical decision analysis. This technique provides a quantitative approach to the comparison of different treatment options. The objectives are: first, to analyze the different strategies for prophylaxis and determine the preferred strategy; and second, to determine to what extent the results obtained are sensitive to the uncertainties of our current knowledge, and to identify areas for further research.

\section{METHODS}

Eligibility for prophylaxis: Infants less than one year of age, who are proven to have perinatally-acquired HIV infection, are eligible for prophylaxis and face one of the three management options described below.

Alternative strategies for prophylaxis: In the first alternative (treat all), all asymptomatic HIV-infected infants less than one year of age receive primary PCP prophylaxis using trimethoprim-sulfamethoxazole (TMP-SMX) according to conventional dosing regimens. In the second alternative (treat none), no infant is started on primary prophylaxis. In the third alternative (treat some), infants are stratified to receive primary prophylaxis if they are presumed to be at 'high risk.' Prophylaxis is not given to infants presumed to be at 'low risk'.

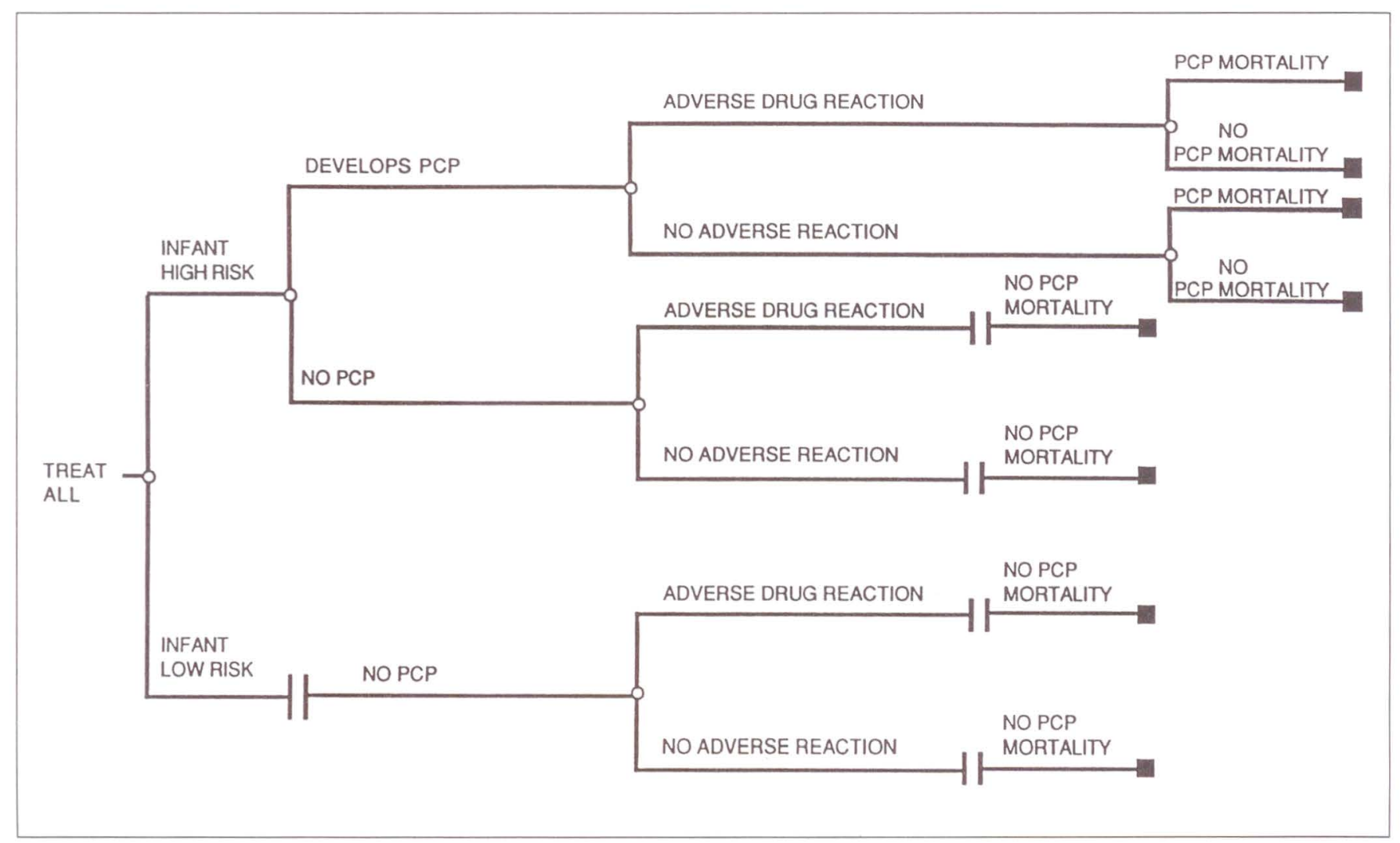

Figure 1) All human immunodeficiency virus-infected infants less than one year of age receive Pneumocystis carinii pneumonia (PCP) prophylaxis 
Risk of PCP in relation to CD4 counts: The predictive values of different cut-off levels of CD4 counts as indicators of an increased risk of PCP in infants less than one year of age are unknown. For the purposes of this study, infants are presumed to be at high risk of developing PCP if their baseline CD4 counts are less than 1500 cells $/ \mathrm{mm}^{3}$ (12). Those who have counts equal to or greater than 1500 cells $/ \mathrm{mm}^{3}$ are presumed to be at low risk.

Decision tree: The decision tree is shown in Figures 1-3. HIV-infected, asymptomatic infants less than one year of age (of HIV-infected mothers) face one of the three prophylaxis options. The decision tree considers events for up to one year after the decision to choose one of the three options. The circles in the decision tree represent chance nodes. Chance nodes are points on the decision tree where events occur naturally based on

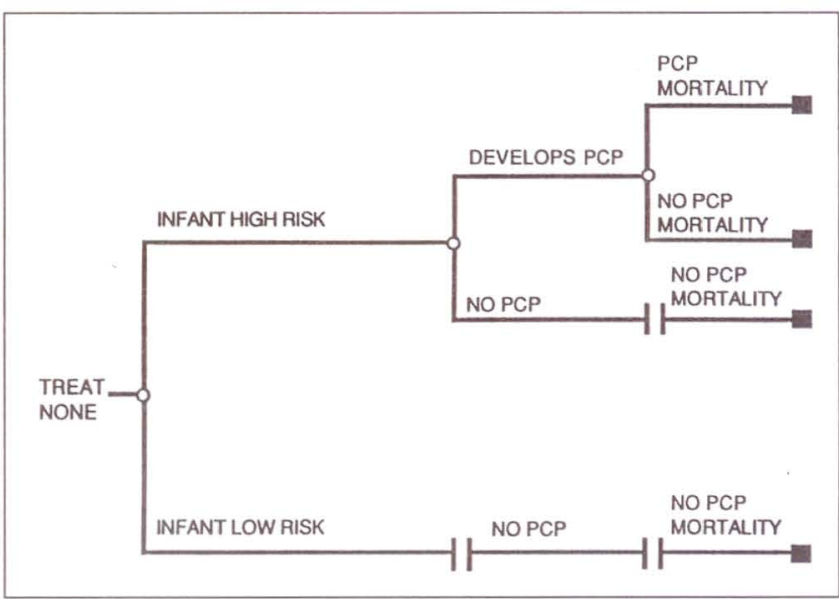

Figure 2) Pneumocystis carinii pneumonia (PCP) prophylaxis is not given to any human immunodeficiency virus-infected infants less than one year of age

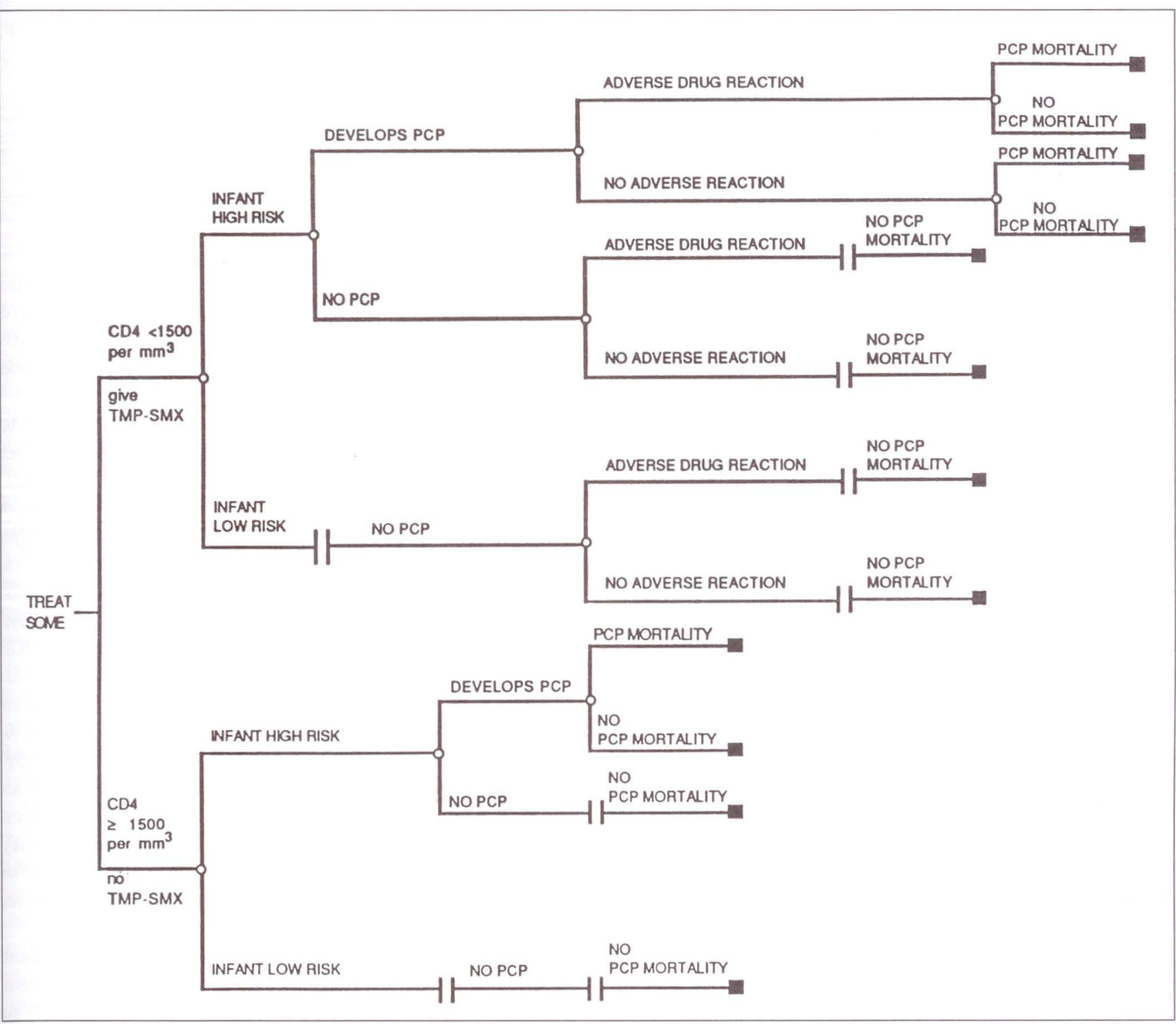

Figure 3) Human immunodeficiency virus-infected infants less than one year of age who have baseline CD4 counts fewer than 1500 cells $/ \mathrm{mm}^{3}$ receive Pneumocystis carinii pneumonia (PCP) prophylaxis. Infants with $\mathrm{CD} 4$ counts equal to or greater than 1500 cells $/ \mathrm{mm}^{3}$ do not recieve prophylaxis 
TABLE 1

Summary of probability estimates

\begin{tabular}{lcc}
\hline Variable & Estimate & $\begin{array}{c}\text { Range of sensitivity } \\
\text { analysis }\end{array}$ \\
\hline Risk of PCP* & 0.50 maximum & $0.1-0.5$ \\
Risk of death & 0.10 minimum & $0-1.0$ \\
TMP-SMX toxicity & 0.70 & $0-1.0$ \\
Sensitivity & 0.25 & $0-1.0$ \\
Specificity & 0.90 & $0-1.0$ \\
Effectiveness of & $\leq 0.50$ & $0.5-1.0$ \\
TMP-SMX & 0.95 & $0.50-0.90$ \\
Prevalence of CD4 & $\geq 0.50$ & \\
$<1500$ cells /mm & & \\
\hline PCP Pneumocystis carinii pneumonia; TMP-SMX & Trimethoprim-sulfa- \\
methoxazole; "Repeated with different values for PCP risk (Table 3)
\end{tabular}

their respective probabilities.

In the 'treat all' option (Figure 1) HIV-infected infants are divided into those who are 'true high risk' and those who are 'true low risk'. The assumption is that infants who are truly at low risk of developing PCP would not do so during the first year of life. While on TMP-SMX, infants in the 'treat all' option may develop adverse side effects. Each infant who develops PCP had one of two short term outcomes: death or survival in year 1 . The highest number of complications related to drug toxicity and the lowest number of cases of PCP are both expected in the 'treat all' option.

In the 'treat none' option (Figure 2), HIV-infected infants fall into the 'true high risk' or 'true low risk' categories. Infants in the true high risk category may develop PCP as a result of chance. If they acquire PCP, the short term outcome is PCP-related death in year 1 or survival beyond year 1 .

The structure of the 'treat some' component is a combination of the other two alternatives (Figure 3). Thus, if the infant is 'presumed low risk' as a result of CD4 testing, no prophylaxis is given and, hence, the sequence of events is like the 'treat none' option. If the infant is 'presumed high risk', prophylaxis is given and the sequence of events is like the 'treat all' option.

Baseline probabilities (Table 1): The probability of each event occurring in the decision tree was obtained from the literature. If specific data were not available in the published articles, the particular authors were contacted in writing.

There is difficulty in defining the denominator of previously asymptomatic HIV-infected infants. Estimates of the incidence of PCP in the first year of life vary from 7.7 to $14 \%(3,13-14)$. However, CDC surveillance data indicate that for children diagnosed with AIDS in the first 12 months of life, 53\% had PCP (15). Therefore, it is expected that the incidence of PCP among previously asymptomatic infants would be less than 53\%; however, the maximum incidence is not established.

This study used a baseline assumption that without prophylaxis, a minimum of $10 \%$ and a maximum of $50 \%$ of HIV-infected infants diagnosed in the first year of life develop PCP during the first year of life. The maximum estimate $(50 \%)$ was used as the baseline estimate. However, because of the uncertainty associated with this estimate, the analyses were repeated using values ranging from 10 to $50 \%$ in order to test the effect on the conclusions.

The effectiveness of TMP-SMX in preventing PCP is well documented (16-18). A baseline estimate of 95\% effectiveness was used in this study.

Adverse reaction rates among HIV-infected children to TMP-SMX range from $14.7 \%$ (19) to $34 \%$ (9). The analyses were based on the fact that the majority of adverse effects are cutaneous (maculopapular or urticarial rashes). A baseline estimate of $25 \%$ was used, with alternative estimates ranging from 0 to $50 \%$.

'Test' refers to a CD4 count of fewer than 1500 cells $/ \mathrm{mm}^{3}$ as a predictor of the risk of acquiring PCP. The magnitude of the presumed risk of acquiring PCP is dependent on the sensitivity and specificity of a CD4 count of fewer than 1500 cells $/ \mathrm{mm}^{3}$ as a predictive test of the probability of an HIV-infected infant developing PCP. Published data are limited regarding the sensitivity and specificity of baseline CD4 counts as indicators of the subsequent risk of development of PCP in children.

The sensitivity of a CD4 count fewer than 1500 cells $/ \mathrm{mm}^{3}$ as an indicator of risk of PCP was estimated to be $89.4 \%$, with a range of 70 to $90 \%(3,5,8-9,14,20$ 23). The baseline estimate used in the decision analysis was $90 \%$.

In order to estimate specificity, it was necessary to obtain data not available in the primary studies above. Thus, additional data were supplied by personal communication with two of three authors from whom data were requested. Data obtained from these two studies $(21,22)$ resulted in specificity estimates of 43 and $47 \%$, respectively. Given that a high specificity value would not be expected for a CD4 count of fewer than 1500 cells/ $\mathrm{mm}^{3}$ as an indicator of subsequent development of PCP in an HIV-infected infant less than one year of age, the baseline analysis was based on the assumption that specificity would not be expected to be greater than $50 \%$.

A baseline CD4 count of less than 1500 cells $/ \mathrm{mm}^{3}$ was used as a surrogate marker of the probability of an infant less than one year old developing PCP. Data from two cohorts $(21,22)$ enabled us to base the primary analysis on the assumption that a minimum of $50 \%$ of asymptomatic HIV-infected infants have CD4 counts fewer than 1500 cells $/ \mathrm{mm}^{3}$.

The analyses considered the probability of an infant who had an episode of PCP dying during the first year of life. The prognosis following an episode of PCP in infancy is poor $(3,5,15,23)$. Overall, surveillance data indicate that one-year mortality rate is $70 \%$ for children under 12 months of age with PCP (15). 
Measurement of outcome: The terminal nodes (blackened squares) at the end of each branch of the decision tree represent the various short term health states that may result by choosing a given option. For example, the uppermost terminal node in Figure 1 represents the outcome state of a child who was started on PCP prophylaxis, developed drug toxicity and died within one year of acquiring PCP. The second uppermost terminal node in Figure 1 represents the health state of a child who was started on prophylaxis, developed drug toxicity, but survived an episode of PCP.

The outcomes (health state preference values) for the various health states are referred to as utilities. This is a well established measure of quantifying the values that individuals place on different health states, based on utility theory (24). The latter describes how individuals are expected to behave when faced with decision making under uncertainty (25). Each health state was assigned a utility value that quantified preferences for the respective health states. This measure of the preference for individual health states resulting from a particular (prophylaxis) strategy can be used to assist the decision maker in determining overall preference for a given strategy.

Death was assigned a utility value of 0 and perfect health a value of 1 . These are the ends of the utility scale, respectively. The remaining utilities were derived by studying 12 medical and nonmedical personnel, using the standard gamble technique for determining utilities (26). The standard gamble technique requires that subjects assign probabilities to a hypothetical gamble between the best and the worst health states, such that the health state being measured is not less preferred or more preferred than a gamble offered (27). The use of medical and nonmedical personnel facilitates the quantitation of the values of different health states from a societal perspective.

The preference that one wishes to measure is that of the patient. Given that infants cannot assist in the determination of their own preferences, it is common practice to ask adults to determine such preferences by presenting them with health state scenarios and asking them to put themselves in the place of the child. Sensitivity analyses are then used to examine the effect of any assumptions made regarding estimates of utilities. This strategy was used in the present study.

An additive utility function was assumed (28). For example, for an infant who dies following PCP, utility is 1 minus the disutility associated with death. The disutilities are summarized in Table 2 and reflect the extent to which each health state preference is less than 1 . Health states that are more desirable have smaller disutility values and greater utility values; thus perfect health has a disutility value of 0 and a utility value of 1 ( 1 minus 0 ). Analytical strategy: The analyses were conducted using the decision analysis software, SMLTREE (J Hollenberg MD, New York). The preferred option is the one with
TABLE 2
Disutility values related to pneumocystis prophylaxis among human immunodeficiency virus (HIV)-positive infants

\begin{tabular}{lccc}
\hline & & & $\begin{array}{c}95 \% \\
\text { confidence } \\
\text { interval }\end{array}$ \\
\hline $\begin{array}{l}\text { Health states } \\
\text { HIV-negative } \\
\text { Full health }\end{array}$ & Disutilities* $^{*}$ & Ranges & - \\
$\begin{array}{l}\text { HIV-positive } \\
\text { Asymptomatic }\end{array}$ & 0 & - & \\
$\begin{array}{l}\text { Adverse drug } \\
\text { reaction }\end{array}$ & 0.50 & $0.08-0.99$ & $0.30-0.70$ \\
$\quad \begin{array}{l}\text { Pneumocystis } \\
\text { pneumonia }\end{array}$ & 0.78 & $0.08-0.99$ & $0.36-0.76$ \\
Death & 1 & $0.35-0.99$ & $0.67-0.89$ \\
\hline
\end{tabular}

"Disutility = 1-utility; ${ }^{\dagger}$ Average values derived using a sample of medical and nonmedical personnel (two clerical staff, two laboratory technologists, two research nurses, two nurses working with acquired immunodeficiency syndrome patients, four subspecialty fellows)

TABLE 3

Preferred options for different risks of Pneumocystis carinii pneumonia (PCP)

\begin{tabular}{lcccc}
\hline & \multicolumn{3}{c}{ Expected utilities } & Preferred \\
PCP risk & Treat all & Treat some & Treat none & option \\
\hline 0.50 & 0.47971 & 0.47389 & 0.39150 & Treat all \\
0.30 & 0.48182 & 0.48013 & 0.43490 & Treat all \\
0.25 & 0.48235 & 0.48169 & 0.44575 & Treat all \\
0.20 & 0.48288 & 0.48325 & 0.45660 & Treat some \\
0.10 & 0.48394 & 0.48638 & 0.47830 & Treat some \\
0.00 & 0.48500 & 0.48950 & 0.50000 & Treat none \\
\hline
\end{tabular}

the highest expected utility value. The expected utility for each alternative is derived by multiplying the probability of each health state outcome by its utility value and summing the results. Expected utility values are often very close numerically, but the margin of differences will change with changes in baseline probabilities.

In recognition of the fact that some variables are associated with varying degrees of uncertainty, the effect of varying baseline variables was studied by conducting one-way as well as threshold sensitivity analyses. In the former, one variable is varied, while in the latter more than one of the more important variables are varied simultaneously.

\section{RESULTS}

Baseline analysis and the effect of PCP incidence: The expected utilities of the three options are shown in Table 3. The baseline results indicate that the 'treat all' option has the highest expected utility and is the preferred strategy overall if the maximum estimate of the incidence of PCP is equal to or greater than $25 \%$; however, Table 3 shows that the 'treat some' option is preferred if the incidence of PCP is less than $25 \%$, but 


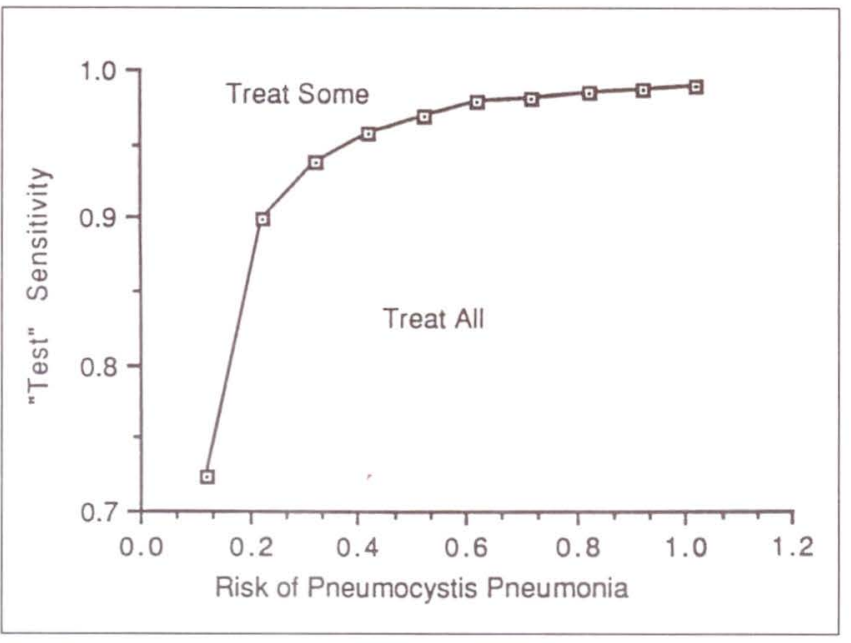

Figure 4) The effect of varying 'test' sensitivity and prevalence of Pneumocystis carinii pneumonia (PCP) simultaneously. 'Test' refers to a CD4 count of fewer than 1500 cells $/ \mathrm{mm}^{3}$ as a predictor of subsequent $P C P$ in a previously asymptomatic human immunodeficiency virus-infected infant. Combinations of values above the curve favour the 'treat some' option: combinations below the curve favour the 'treat all' option; combinations along the curve represent the indifference points

greater than $0 \%$. In this regard, prophylaxis would be recommended for those infants who have baseline CD4 counts of fewer than 1500 cells $/ \mathrm{mm}^{3}$.

One-way sensitivity analyses: If the proportion of infants with baseline CD4 counts fewer than 1500 cells $/ \mathrm{mm}^{3}$ exceeds $30 \%$, the 'treat all' option is preferred. In the analyses, this percentage corresponds to the proportion of infants presumed to be at high risk of acquiring PCP.

The 'treat some' option is the preferred option if the sensitivity of a CD4 count of fewer than 1500 cells $/ \mathrm{mm}^{3}$ as a test indicating risk of PCP is equal to or greater than 98\%; otherwise the 'treat all' option remains the preferred alternative. Changes in specificity did not change the preferred option.

The threshold level of effectiveness of TMP-SMX that favoured a decision to treat all infants is $45 \%$. If the drug is less than $45 \%$ effective in preventing PCP, the 'treat some' strategy is preferred.

The results suggest that if the proportion of infants experiencing significant drug-related toxicity is equal to or greater than $60 \%$, the 'treat some' option becomes preferred; below $60 \%$ the 'treat all' option is preferred.

The analyses suggest that the 'treat all' option is preferred regardless of PCP-related mortality, indicating that concerns regarding morbidity also influence decision making.

The results of sensitivity analyses conducted on the utility values indicate the following: first, that the "treat some' option is preferred if the disutility associated with HIV seropositivity is greater than 0.90 ; thus, 'treat some' only becomes the strategy of choice when the disutility exceeds the upper limit of the $95 \%$ confidence
TABLE 4

'Treat all' versus 'treat some' option: Threshold values of risk of PCP for estimates of risk of pneumocystis-related death and test sensitivity

\begin{tabular}{ccc}
\hline pDeath & Sensitivity $^{*}$ & Threshold of pPCP $^{\dagger}$ \\
\hline 0.50 & 0.80 & 0.14 \\
0.50 & 0.90 & 0.18 \\
0.50 & 0.95 & 0.45 \\
0.70 & 0.80 & 0.13 \\
0.70 & 0.90 & 0.16 \\
0.70 & 0.95 & 0.40 \\
0.80 & 0.80 & 0.12 \\
0.80 & 0.95 & 0.38 \\
0.90 & 0.80 & 0.12 \\
0.90 & 0.95 & 0.36 \\
1.0 & 0.95 & 0.35 \\
\hline
\end{tabular}

PCP Pneumocystis carinii pneumonia; pDeath Probability of PCP-related death: PPCP Probability of PCP: "Sensitivity of CD4 count of fewer than 1500 cells $/ \mathrm{mm}^{3}$ as indicator of risk of PCP, ' Levels of risk of PCP at which one is indifferent between the 'treat all' and 'treat some' options

interval $(\mathrm{CI})$ of the estimate used in the analysis (at a $95 \% \mathrm{CI}$, disutility ranges from 0.30 to 0.70 ). Second, that the expected utility values of all three options fall as the risk of PCP increases; however, the preferred option remains the 'treat all' option throughout the 95\% CI range of values. Finally, as Table 2 shows, the disutility attributed to the combination of HIV seropositivity and adverse drug reaction is 0.56 . The analyses indicated that if the disutility attributable to HIV seropositivity and adverse drug reaction exceeds 0.65 , the 'treat some' option becomes the preferred option. This estimate falls within the 95\% CI of the estimate used in the baseline analysis.

Figure 4 shows an example of the threshold analyses conducted, in this case the effect of varying test sensitivity and the incidence of PCP simultaneously. Combination of values along the curve would result in an indifference to either of the 'treat all' and the 'treat some' options.

Table 4 shows the result of a three-way analysis where the threshold values of the proportion of PCP are determined for different values of sensitivity and probability of PCP related death for the 'treat all' versus the 'treat some' option. For example, if the risk of PCP related death is $50 \%$ and 'test' sensitivity is $80 \%$, one would be indifferent to the 'treat all' versus 'treat some' options, if the risk of PCP is $14 \%$.

\section{DISCUSSION}

The results indicate that if the incidence of PCP is equal to or greater than $25 \%$, the preferred PCP prophylaxis strategy involves administration of prophylaxis to all HIV-infected infants regardless of $\mathrm{CD} 4$ counts. However, if the risk of PCP among HIV-infected infants is less than $25 \%$, it is justifiable to give prophylaxis to those infants with CD4 counts of fewer than 1500 cells $/ \mathrm{mm}^{3}$. 
This concurs with the finding that the 'treat some' strategy is preferred if the proportion of infants with CD4 counts of fewer than 1500 cells $/ \mathrm{mm}^{3}$ is less than $30 \%$.

If the risk of PCP is $50 \%$, a test used to identify HIV-infected infants at risk of PCP should have a sensitivity of greater than $98 \%$. It is unlikely that a CD4 count of fewer than 1500 cells $/ \mathrm{mm}^{3}$ would consistently achieve this desired level of sensitivity. However, if the prevalence of PCP is less than 25\%, the level of sensitivity needed would be lower and could be achieved.

The fact that the 'treat all' option is preferred, regardless of PCP-related mortality, underscores the importance of morbidity concerns regarding PCP. In this regard, one of the psychosocial benefits in preventing PCP is the reduction of the chance of disclosure of HIV infection.

In this study, the percentage of CD4 cells was not considered in order to simplify the analyses. However, clinicians may choose to examine whether the combination of a cut-off of $20 \%$ CD4 counts and a cut-off of 1500 cells $/ \mathrm{mm}^{3}$ would result in a sensitivity level of greater than 98\%. Even if such a level is not achieved, the threshold analyses facilitate decision making. For example, as the sensitivity falls the probability of acquiring PCP must be lower for one to become indifferent between the 'treat some' option and the 'treat all' option (Figure 4).

This study did not analyze prophylaxis options for infants with indeterminate status, rather it addressed prophylaxis options for infants who are regarded by their clinicians as being HIV-infected. The proportion of HIV-infected infants in the former group will become

ACKNOWLEDGEMENTS: We are grateful to Drs Moore and Blanche who kindly supplied additional data relating to references (21) and (22), respectively.

\section{REFERENCES}

1. Kovacs JA, Masur H. Pneumocystis carinii pneumonia: Therapy and prophylaxis. J Infect Dis 1988;158:254-9.

2. Centers for Disease Control. Update: Acquired immunodeficiency syndrome-United States. MMWR 1986;35:542.

3. Scott GB, Hutto C, Makuch RW, et al. Survival in children with perinatally acquired human immunodeficiency virus type 1 infection. N Engl $J$ Med 1989;321:1-6.

4. Krasinski K, Borkowsky W, Holzman RS. Prognosis of human immunodeficiency virus infection in children and adolescents. Pediatr Infect Dis J 1989;8:216-20.

5. Bernstein LJ, Bye MR, Rubinstein A. Prognostic factors and life expectancy in children with acquired immunodeficiency syndrome and Pneumocystis carinii pneumonia. Am J Dis Child 1989;143:775-8.

6. Phair J, Munoz A, Detels R, et al. The risk of Pneumocystis carinii pneumonia among men infected with human immunodeficiency virus type 1. N Engl J Med 1990;322:161-5.

7. Sanders-Laufer D, Burroughs M, Marshall F, et al. Pneumocystis carinii pneumonia (PCP) in 'low-risk' smaller as advanced polymerase chain reaction technology becomes more available to most Canadian centres following HIV-infected children. To implement the findings of our study, a diagnosis of HIV infection has to be made. Continued improvement in the diagnosis of perinatally-acquired HIV infection will enable the early introduction of preventive measures such as PCP prophylaxis.

Since individual preferences vary in practice, it is important to explore the effects that changes in the utility estimates have on the results. In addition, even though decision analysts may regard numerically close expected utilities as significant, thorough sensitivity analyses are performed to examine the impact of changes in probabilities on such numerically close expected utilities.

In this context, the results were not significantly affected by changes in the utility estimates, with one exception: that attributable to adverse drug reaction. The 'treat some' option is preferred if the disutility (1 minus utility) value for the combination of HIV-seropositivity and adverse drug reaction exceeds 0.65 . However, in practice it is unlikely that the disutility associated with the combination of seropositivity and side-effects would exceed 0.65 and, hence, approach that of a less preferred option such as PCP (disutility = 0.78 ), or even a major but less severe disease than PCP.

In summary, we have presented an approach to arriving at a decision on PCP prophylaxis in infants less than one year of age, using the data that clinicians would use in practice. The results highlight the areas in need of further research in order to improve the degree of certainty associated with certain variables.

HIV-infected children. Pediatr Res 1990;27:183A.

8. Leibovitz E, Rigaud M, Pollack H, et al. Pneumocystis carinii pneumonia in infants infected with the human immunodeficiency virus with more than 450 CD4 T lymphocytes per cubic millimeter. N Engl J Med 1990;323:531-3.

9. Sanders-Laufer D, Debruin W, Edelson PJ. Pneumocystis carinii infections in HIV-infected children. Pediatr Clin North Am 1991;38:69-87.

10. Pizzo PA, Wilfert CM. Treatment considerations for children with human immunodeficiency virus infection. Pediatr Infect Dis J 1990;9:690-9.

11. Hughes WT. Pneumocystis carinii pneumonia. In: Pizzo PA, Wilfert CM, eds. Pediatric AIDS: The Challenges of HIV Infection in Infants, Children and Adolescents. Baltimore: Williams \& Wilkins, 1991:288-98.

12. Centers for Disease Control. Guidelines for prophylaxis against Pneumocystis carinii pneumonia for children infected with human immunodeficiency virus. MMWR 1991;40:1-13.

13. Hsu H, Kunches L, Ng P, Moye J, Makarewicz L, Shea B. Pneumocystis carinii pneumonia in infants with human immunodeficiency virus infection. Presented at the 30th Interscience Conference on Antimicrobial Agents and Chemotherapy, Atlanta, 1990. (Abs 417)

14. Kovacs A, Frederick T, Church J, Eller A, Oxtoby M, Mascola L. CD4 T-lymphocyte counts and Pneumocystis 
carinii pneumonia in pediatric HIV infection. JAMA 1991;265:1698-703.

15. Oxtoby MJ. Perinatally acquired human immunodeficiency virus infection. Pediatr Infect Dis $\mathrm{J}$ 1990;9:609-19.

16. Hughes WT, Kuhn S, Chaudhary S, et al. Successful chemoprophylaxis for Pneumocystis carinii pneumonitis. N Engl J Med 1977;297:1419-26.

17. Hughes WT, Rivera GK, Schell MJ, Thornton D, Lott L. Successful intermittent chemoprophylaxis for Pneumocystis carinii pneumonitis. N Engl J Med 1987;316:1627-32.

18. Fishl MA, Dickinson GM, La Voie L. Safety and efficacy of sulfamethoxazole and trimethoprim chemoprophylaxis for Pneumocystis carinii pneumonia in AIDS. JAMA 1988;259:85-9.

19. McSherry G, Wright M, Oleske J, Connor E. Frequency of serious adverse reactions (SAR) to trimethoprimsulfamethoxazole (TMP-SMZ) and Pentamidine (P) among children with human immunodeficiency virus type 1 (HIV-1) infection. In: Programs and Abstracts of the 28th Interscience Conference on Antimicrobial Agents and Chemotherapy. Los Angeles, 1988:353. (Abst 1357)

20. Ruthstein RM. Predicting risk of Pneumocystis carinii pneumonia in human immunodeficiency virus-infected children. Am J Dis Child 1991;145:922-4.

21. Moore EC, Cohen F. Pneumocystis carinii pneumonia in HIV-infected infants under 6 months of age. Sixth Annual National Pediatric AIDS Conference. Washington 1991:40.

22. Blanche S, Tardieu M, Duliege A-M, et al. Longitudinal study of 94 symptomatic infants with perinatallyacquired human immunodeficiency virus infection. Am J Dis Child 1990;144:1210-5.

23. Connor E, Bagarrazzi M, McSherry, et al. Clinical and laboratory correlates of Pneumocystis carinii pneumonia in children with HIV. JAMA 1991;265:1693-7.

24. von Neumann J, Morganstern O. Theory of Games and Economic Behaviour, 3rd edn. New York: Wiley, 1953.

25. Holloway CA. Decision Making Under Uncertainty: Models and Choices. Englewood Cliffs: Prentice Hall, 1979.

26. Torrance GW. Utility approach to measuring healthrelated quality of life. J Chron Dis 1987;40:593-600.

27. Weinstein MC. Challenges for cost-effectiveness research. Med Decis Making 1986;6:194-8.

28. Fisher GW. Utility models for multiple objective decisions: Do they accurately represent human preferences? Decis Sci 1979:10:451-79. 


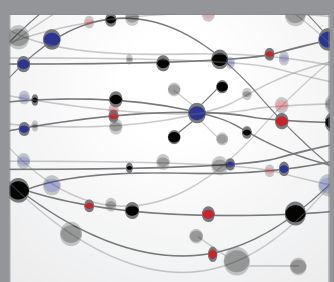

The Scientific World Journal
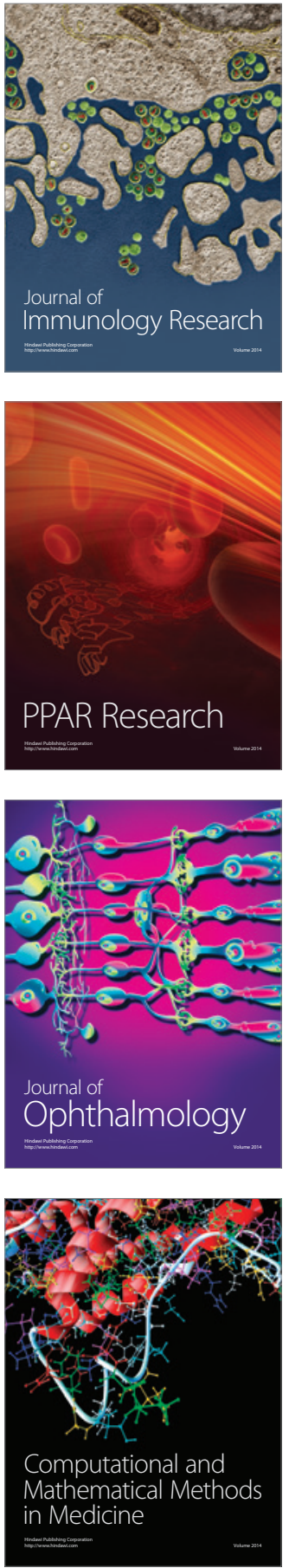

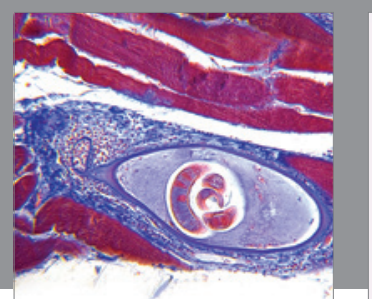

Gastroenterology Research and Practice

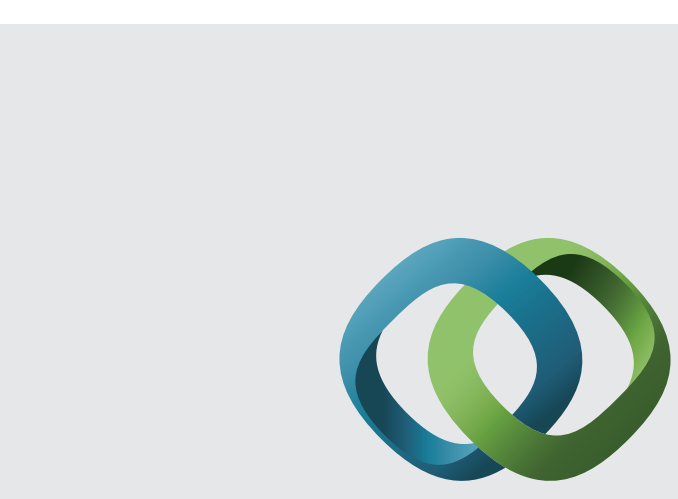

\section{Hindawi}

Submit your manuscripts at

http://www.hindawi.com
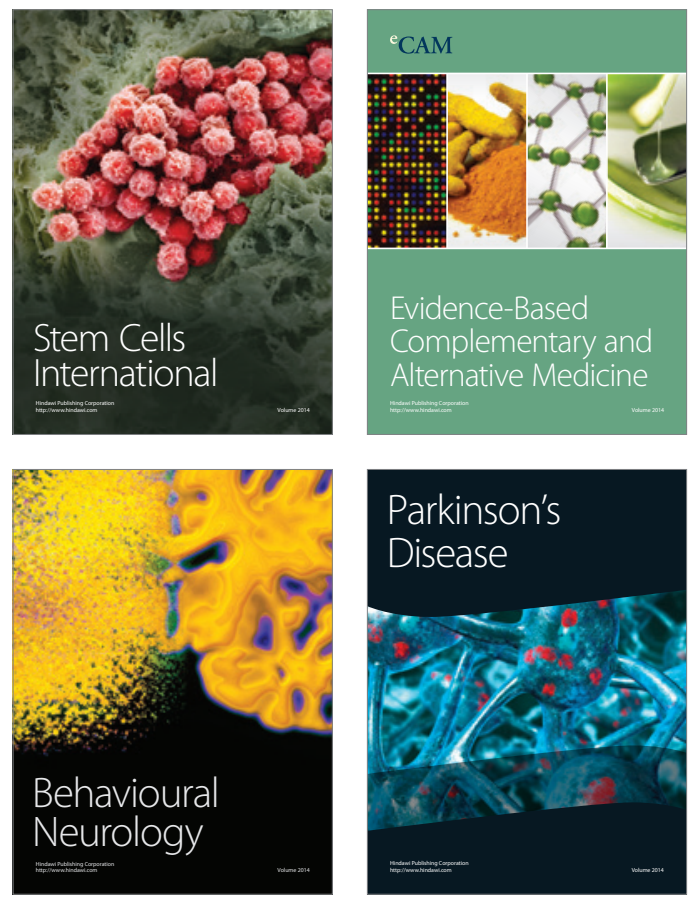
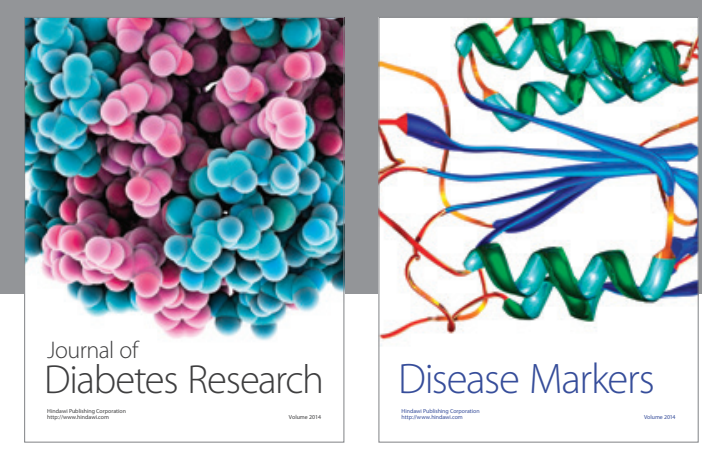

Disease Markers
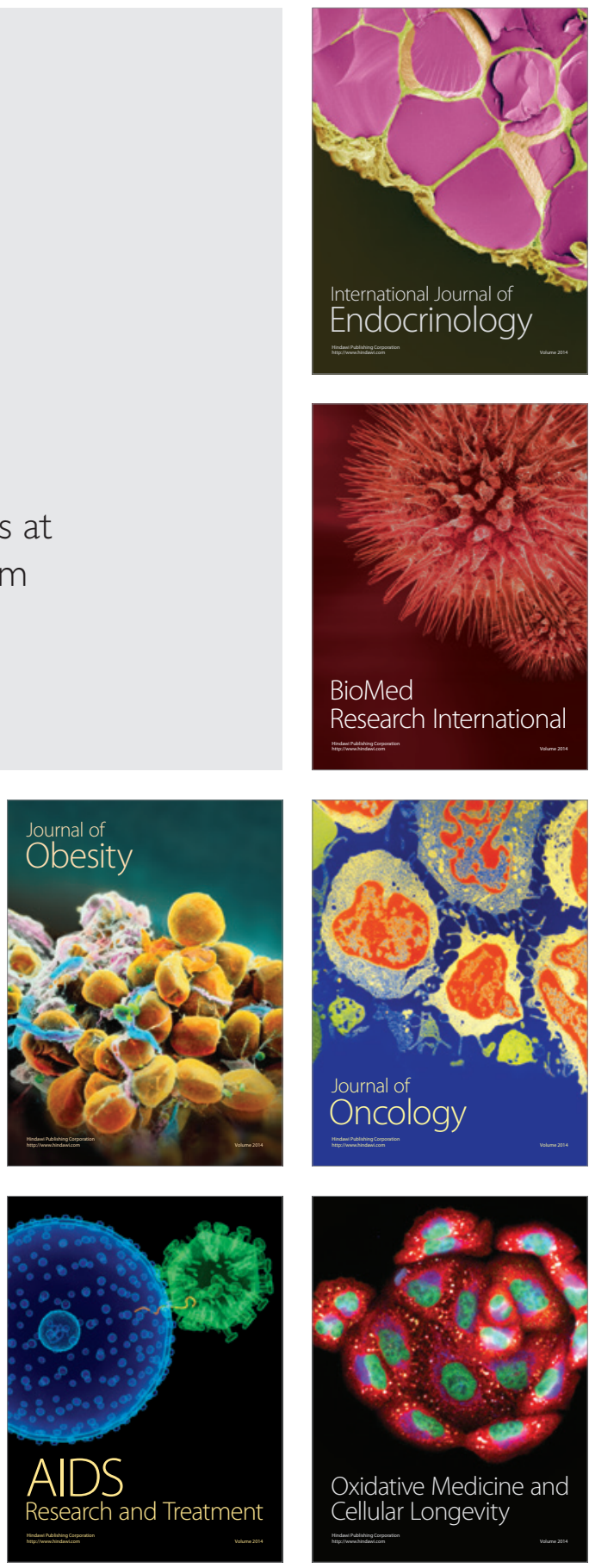